\title{
The use of the EMG signal for the arm model control
}

\author{
Grzegorz Trzmiel ${ }^{1, *}$, Dariusz Kurz ${ }^{1}$, and Wiktor Smoczyński ${ }^{1}$ \\ ${ }^{1}$ Poznan University of Technology, Faculty of Electrical Engineering, Piotrowo 3A, 60-965 Poznan, Poland
}

\begin{abstract}
The article presents the design of the control system and prototype of a robot arm controlled by electromyographic (EMG) signals. It includes the characteristics and method of measurement of the EMG signals, the concept of application of the measured signals to control the model of a human hand and the description of the control system. The design of a device including the specification of the used subassemblies was developed. As well as this, the physical object and various options for its application were presented.
\end{abstract}

\section{Introduction}

\subsection{Electromyography (EMG)}

The pioneer of clinical electromyography which gives real benefits to medicine was Fritz Buchthal and his school which became the largest centre for research on electromyography in 1950s. In 1970s. computers took over the tasks related to measurements and calculations, which ensured the objectivity of research and shortened the time required for giving a diagnosis. The miniaturisation of the computers and development of robotics created possibilities for using EMG not only for medical examinations, but also for designing electrically powered prostheses [2].

\subsection{Limb prostheses}

Contemporary limb prosthetics is a difficult concept, which combines aspects of both engineering and medicine. The creation of prosthetic limbs requires expertise in anatomy, physiology, mechanics, and frequently also electronics and robotics. Prostheses which derive energy from muscles of a user are relatively cheap to construct and repair, but unfortunately, there is a problem of the lack of a possibility of conscious control of movement by the user, which worsens their functionality. Electrically powered prostheses are an interesting option, and one of the methods of operation of such prostheses is the application of an electric signal coming from user muscles, measured by means of an electromyograph (EMG) $[1,4]$.

The application of the EMG signal for control is not limited only to prosthetics. It can also be used for remote operation or in the form of an exoskeleton of robots functioning under working conditions which are detrimental and dangerous to humans, in tasks which require high accuracy, e.g. the operation of industrial processes or defusion of bombs [7].

\section{EMG SIGNAL}

\subsection{EMG signal and muscle work}

The EMG measurement takes into account both the evaluation of the resting activity of a muscle, i.e. the activity in a relaxed state and during work (contraction). There are discharges during the contraction process, whose amplitude depends on the muscle tension force (fig. 1).

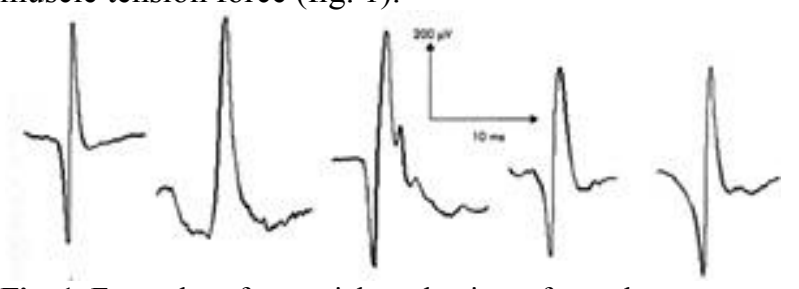

Fig. 1. Examples of potentials at the time of muscle contraction [2].

Professional EMG tests take into account many other parameters such as e.g. duration, shape or frequency of discharges (fig. 2).

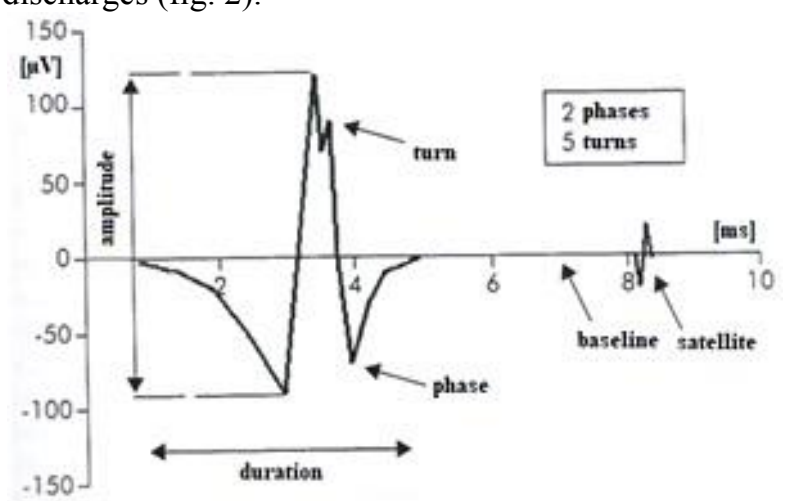

Fig. 2. Parameters measured during the EMG test [2].

The measurement is affected significantly by the location of the measuring electrode, therefore, each

Corresponding author: grzegorz.trzmiel@put.poznan.pl 
time a person is connected to the apparatus, it is necessary to calibrate the measuring equipment.

\subsection{EMG sensor}

Contemporary EMG sensors are provided with electrodes (needle and surface electrodes), amplifiers and filters (low- and high-pass filters). Needle electrodes are used for measurements which require the highest measurement accuracy, however a test performed with such electrodes is painful and requires the puncture of a muscle by the electrode. Surface electrodes in the form of round or rectangular metal parts are used more frequently.

During the measurement, a set of three electrodes is used: one of them is placed on the head, the second one on the muscle insertion and the third one functions as an earth electrode, which determines the reference level for the amplifiers.

An important element of the correct EMG measurement is the faithful reproduction of the tested signals within the whole spectrum of phases and frequencies at simultaneous rejection of others which could interfere with the results [6].

\section{ARM PROTOTYPE CONTROL SYSTEM}

The project involved making an attempt at designing and constructing a robot arm controlled by the EMG signals. During the works, the method of implementation of the device as the human hand model controlled by a signal coming from a user's biceps and triceps muscles was implemented. In order to process the signal read from the sensor into the signal that controls the operation of the robot, the Arduino system whose operation is based on the proprietary software, was selected. The control system was programmed and verified (also including its calibration) using the dedicated Arduino IDE environment [3]. Figures 3 and 4 present the diagrams according to which the device was constructed.

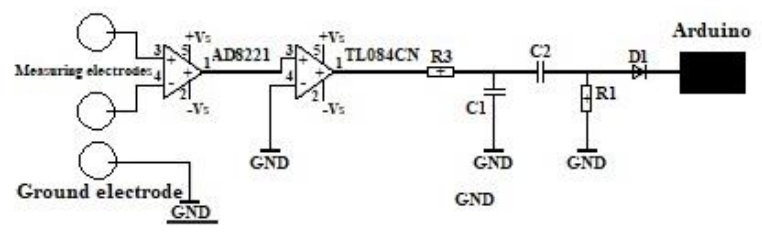

Fig. 3. Diagram of the designed EMG sensor [5].

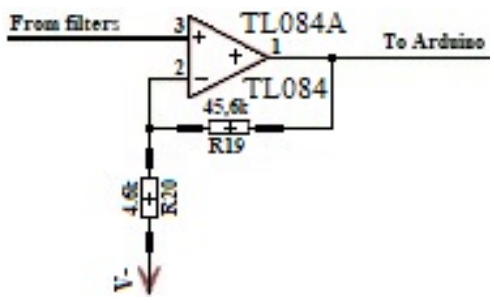

Fig. 4. Diagram of the TL084 amplifier operating in the closed feedback loop.

Primary filters visible in the diagram, fig. 5, allow for the passing of frequencies ranging between 55 and 91
$\mathrm{Hz}$. The use of amplifying elements allowed for the selection of the tension thresholds read on the ADC, above which a muscle contraction took place. Fig. 6 presents a photograph of the model of a hand and a forearm made of plywood, including visible servomechanisms.

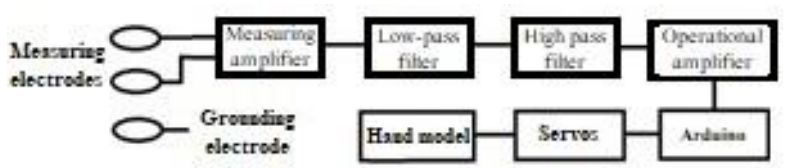

Fig. 5. Block diagram of the designed device [5].

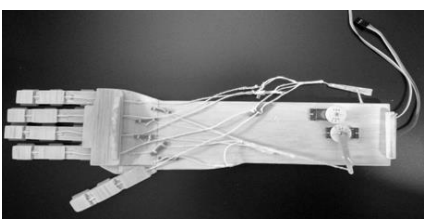

Fig. 6. Arm/hand model used in the project [5].

\section{Summary}

One of the most important applications of the EMGcontrolled devices is the limb prosthetics. If the loss of a limb was partial and some muscles are still preserved, electromechanical prostheses controlled by EMG signals are considered one of the best prospects for such persons. In such a prosthesis, the role of the muscles which trigger the movement of the healthy limb is fulfilled by servomechanisms which cause the movement of the hand model. As opposed to exclusively mechanical prostheses, the prostheses which take advantage of the EMG signals to control the servomechanisms may be used by persons whose physical strength is poor.

\section{References}

1. I. Elamvazuthi, S. Parasuraman, Procedia Comp. Science 76 (2015).

2. B. Emeryk-Szajewska, M. Niewiadomska-Wolska, Neurofizjologia kliniczna. Elektromiografia $i$ elektroneurografia Tom I, Wyd. Medycyna Praktyczna, Kraków (2008).

3. T. Francuz, Język C dla mikrokontrolerów, od podstaw do zaawansowanych aplikacji, Helion, Gliwice (2011).

4. M. Magda, EMG Signal Models - a Short Review, Badania i Rozwój Młodych Naukowców w Polsce. Nauki techniczne i inżynieryjne Część I, Wyd. Młodzi Naukowcy, Poznań (2016).

5. W. Smoczyński, Projekt ramienia robota sterowanego sygnatem EMG, Praca dyplomowa inżynierska, Politechnika Poznańska (2018).

6. S. Sudarsan, E. Chandra Sekaran, Procedia Engineering 38 (2012).

7. http://www.instructables.com: DIY Muscle Sensor / EMG Circuit for a Microcontroller (14.12.2018)

Corresponding author: grzegorz.trzmiel@put.poznan.pl 